\title{
Evaluation of the Effects of One versus 4 Weeks Activation Intervals on the Rate of Orthodontic Tooth Movement: An Experimental Study
}

\author{
Mahmoud Elseidy ${ }^{1 *}$ (D), Yehya A. Mostafa ${ }^{1}$, Sammah S. Mehanni ${ }^{2}$, Fouad A. El-Sharaby ${ }^{3}$ \\ ${ }^{1}$ Department of Orthodontics, Faculty of Dentistry, Future University in Egypt, New Cairo, Egypt; ${ }^{2}$ Departmentof Oral Biology, \\ Faculty of Dentistry, Cairo University, Giza, Egypt; ${ }^{3}$ Department of Orthodontics, Faculty of Dentistry, Cairo University, Giza, \\ Egypt
}

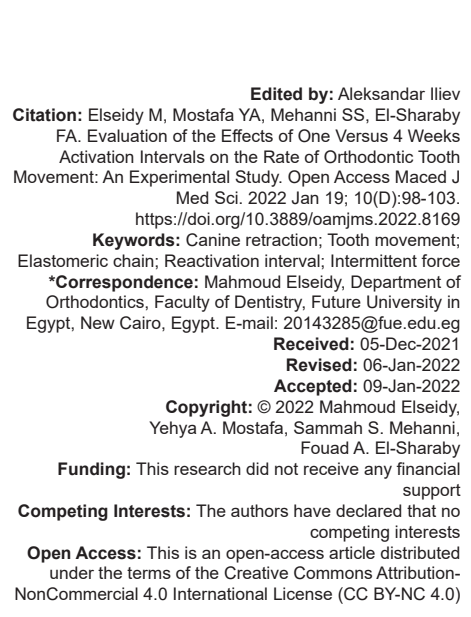

\section{Abstract}

AIM: The study aims to evaluate the effects of 1 week versus 4 weeks reactivation of the elastomeric chain on the rate of orthodontic tooth movement (OTM) and supporting structures.

METHODS: The $3^{\text {rd }}$ maxillary premolars of 8 male mongrel dogs were extracted. Custom made appliance was constructed so that the $2^{\text {nd }}$ premolars were allowed to slide bodily. An elastomeric chain with calibrated force of $150 \mathrm{~g}$ was attached to the hooks of soldered tubes on the $2^{\text {nd }}$ premolar's crowns. The sample was divided into two groups based on the interval of reactivation of the elastomeric chains used for tooth movement where in group activation was scheduled every 1 week versus 4 weeks in group II. Measurements of the amount and rate of OTM were performed every week for 12 weeks using digital caliper. The animals were then sacrificed and specimens were prepared for decalcified histological examination using Hematoxylin and Eosin stains under light microscope.

RESULTS: No remarkable difference in the rate of OTM between the two groups was reported. The total amount of tooth movement in group I was $1.44 \mathrm{~mm} \pm 0.5$ compared to $1.46 \mathrm{~mm} \pm 0.6$ in group II. Histological examination revealed a more favorable tissue reaction associated with 4 weeks reactivation as regards the new formed bone, root resorption, and periodontal ligament structure.

CONCLUSION: Altering the reactivation interval of the elastomeric chains from 4 to 1 week doesn't have a significant impact on the rate of OTM. However, 4 weeks reactivation interval showed a more favorable tissue reaction associated with OTM.

\section{Introduction}

Tooth movement during orthodontic treatment is basically a result of biological reaction within the periodontal ligaments and alveolar bone evoked by force application in a predetermined direction and magnitude. It is believed that the use of an optimal force system is important for an adequate biological response in the periodontal system. The manner of force application varies between continuous, interrupted and intermittent based on rate of force decay [1]. Interrupted forces were found to be the most favorable method for space closure, when compared to continuous forces as they provide periods of rest which favorably affects cell proliferation in the supporting tissues thus promotes further tissue changes when the appliance is reactivated [2].

Elastic chains have been used extensively in orthodontics for cuspid retraction and general space closure. They are force delivery systems that deliver an interrupted type of force application. The greatest problem associated with elastic chains lies in the loss of power; hence, there is a continuous need for reactivation when being used.

Orthodontic treatment requires multiple appliance reactivations that is usually planned without precise comprehension of the associated biological reaction. Experience has shown that orthodontic appliances should not be reactivated more frequently than 3-weeks intervals. A 4-weeks appointment cycle is more typical in clinical practice. Undermining resorption of the supporting alveolar bone in the direction of tooth movement was reported to require 7-14 days to occur. When this is the mode of tooth movement and when force levels decline rapidly, tooth movement is essentially complete in this length of time. The logic behind the interval between adjustments now becomes clear [1]. Several studies have been conducted exploring optimal force magnitude that delivers the optimal tooth movement and tissue reaction [3]. On the other hand, no firm experimental or clinical data have been reported concerning optimum period for reactivation cycles [1].

The aim of this study was to evaluate the effects of 1 week versus 4 weeks reactivation intervals of elastomeric chains on tooth movement and the 
supporting structures. The Null hypothesis was that no difference exists between 1 versus 4 weeks activation intervals as far as the effect on the rate of tooth movement and supporting structures.

\section{Materials and Methods}

This experimental study was conducted in the animal house of the Faculty of Medicine, Cairo University. The study was approved by the Ethical committee of the Future University in Egypt.

Study design was a split mouth where the sample was divided into two groups based on the interval of reactivation of the elastomeric chains used for tooth movement. Group I the elastomeric chain was reactivated every 1 week. Group II the elastomeric chain was reactivated every 4 weeks.

The sample for this study consisted of 8 adult mongrel dogs with an average weight of 13-17 kg and age between 1 and 3 years. All dogs were confirmed to have full set of permanent teeth.

The $3^{\text {rd }}$ maxillary premolars were extracted. Custom-made crowns with soldered metal tubes to allow a $1 \mathrm{~mm}$ stainless steel wire to pass freely were fitted to the $2^{\text {nd }}$ and $4^{\text {th }}$ premolars so $2^{\text {nd }}$ premolars were allowed to move only by sliding (bodily movement). An elastomeric chain with calibrated force of $150 \mathrm{~g}$ was attached to the hooks of soldered tubes on the premolars' crowns. Indentation was made on the labial surface of the canine using a round bur to be used as a distant reference point for monitoring the amount and rate of tooth movement. The measurements were taken using digital caliper between the indentation made on the labial surface of the canine and $2^{\text {nd }}$ premolar crown tip. Measurements of the amount of tooth movements of the $2^{\text {nd }}$ premolars were performed every week for 12 weeks (Figure 1).

At the end of the experiment (12 weeks), the dogs were humanely sacrificed with an

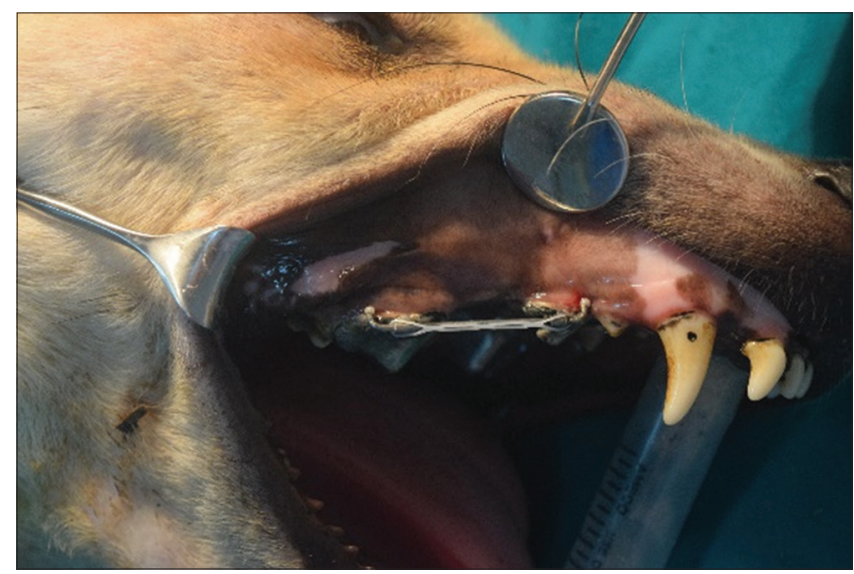

Figure 1: Appliance used with the elastomeric chain and the Indentation made intravenous injection of overdose of pentobarbital $(40-50 \mathrm{mg} / \mathrm{kg})$.

The maxillary segments including the fourth premolar and the second premolar were dissected out en bloc and fixed in 10\% buffered formalin [4]. Blocks were then immersed in $200 \mathrm{ml}$ solution consisted of two mixtures $100 \mathrm{ml}$ concentration for each one (mixture 1 :formic acid $125 \mathrm{ml}$ and distilled water $250 \mathrm{ml}$, while mixture 2:sodium citrate $50 \mathrm{~g}$ and distilled water $250 \mathrm{ml}$ ). The solution was renewed every day for approximately 10 weeks till complete decalcification of the specimen. Inserting a pin directly into the tissues (physical test) was done to confirm complete decalcification. The specimens then were embedded in paraffin, sectioned mesiodistally $(6-8 \mu \mathrm{m})$ with a microtome and stained with Hematoxylin and Eosin (H\&E). These specimens were longitudinally sectioned parallel to the direction of orthodontic traction and examined under the light microscope.

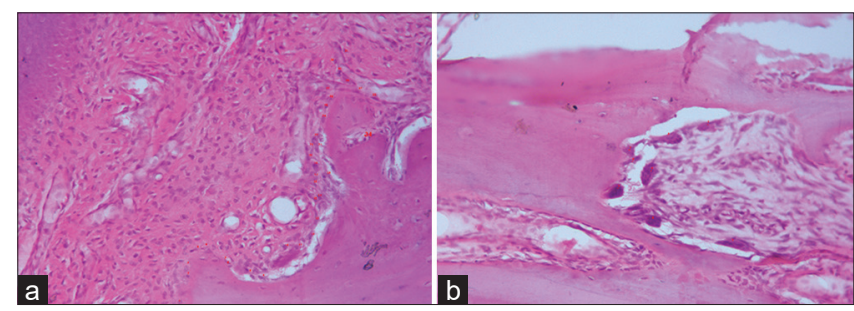

Figure 2: (a) Counting of osteoblasts using leica Qwin 500 software. (b) Counting of osteoclasts using leica Qwin 500 software

All the H\&E sections were examined at magnification $40 \times$ by the image analyzer computer system using the software Leica Qwin 500 (Germany) in the Center of Research, Faculty of Dentistry, Cairo University.

Histomorphometric analysis was done where osteoblasts and osteoclasts were counted using Leica Qwin 500 software (Figure 2). Five fields for each slide were examined using a magnification $\times 100$ and $\times 200$ by light microscopy transferred to the monitor's screen. Mean number of each cell was obtained for each group for evaluation. The examiner N.M.K was blinded to the groups to avoid any bias during interpretation of the histologic sections.

Table 1: The mean, standard deviation (SD) values of tooth movement of different groups

\begin{tabular}{|c|c|c|c|c|c|}
\hline \multirow[t]{3}{*}{ Variables } & \multicolumn{5}{|c|}{ Tooth movement } \\
\hline & \multicolumn{2}{|c|}{ Group I } & \multicolumn{2}{|c|}{ Group II } & \multirow[t]{2}{*}{$p$-value } \\
\hline & Mean & SD & Mean & SD & \\
\hline W1 & 24.47 & 1.83 & 24.69 & 1.69 & 0.685 \\
\hline W2 & 24.89 & 1.70 & 25.05 & 1.49 & 0.731 \\
\hline W3 & 25.00 & 1.75 & 25.33 & 1.39 & 0.501 \\
\hline W4 & 25.11 & 1.76 & 25.39 & 1.38 & 0.559 \\
\hline W5 & 25.17 & 1.80 & 25.44 & 1.36 & 0.597 \\
\hline W6 & 25.26 & 1.84 & 25.53 & 1.37 & 0.612 \\
\hline W7 & 25.36 & 1.87 & 25.65 & 1.34 & 0.581 \\
\hline W8 & 25.51 & 1.95 & 25.79 & 1.35 & 0.608 \\
\hline W9 & 25.52 & 2.10 & 25.81 & 1.48 & 0.643 \\
\hline W10 & 25.65 & 2.12 & 25.90 & 1.47 & 0.691 \\
\hline W11 & 25.74 & 2.17 & 25.97 & 1.48 & 0.718 \\
\hline W12 & 25.91 & 2.14 & 26.15 & 1.56 & 0.714 \\
\hline$p$-value & $<0.001^{*}$ & & $<0.001^{*}$ & & \\
\hline
\end{tabular}




\section{Statistical analysis}

Data were explored for normality using Kolmogorov-Smirnov and Shapiro-Wilk tests. Data showed parametric (normal) distribution. Repeated measure ANOVA was used to compare between more than two groups in related samples. Paired sample t-test was used to compare between two groups in related samples (Split mouth technique). Data were presented as a mean \pm standard deviation values. The significance level was set at $p \leq 0.05$. Statistical

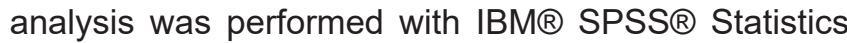
Version 20 for Windows.

\section{Results}

\section{Clinical findings}

The appliances were in place with no signs of tooth hyper mobility or loss during the course of the study. Total amount of tooth movement in group I was $1.44 \pm 0.5 \mathrm{~mm}$ and $1.46 \pm 0.6 \mathrm{~mm}$ in group II.

In both groups, there was a statistically significant difference between $1^{\text {st }}$ week (W1) till $12^{\text {th }}$ week $(W 12)(p<0.001)$. The highest mean value was found in (W12) descending to (W1) (Figure 3).

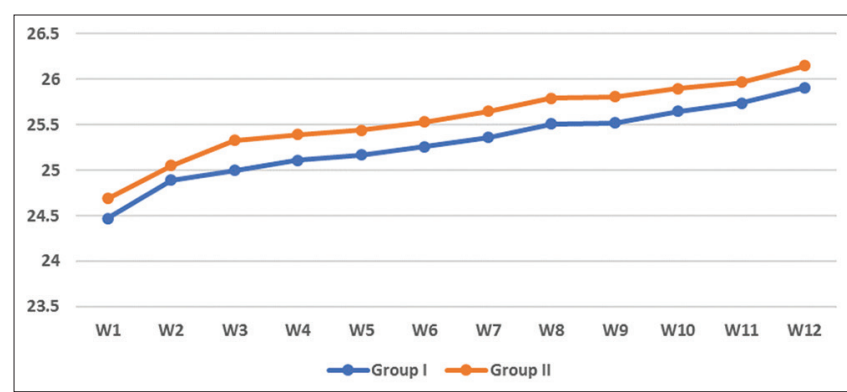

Figure 3: Line chart representing tooth movement for different groups along different time periods

When comparing between the two groups, there was no significant difference concerning the total amount of tooth movement as the mean value for group I was $1.44 \pm 0.5 \mathrm{~mm}$ presented as $0.64 \mathrm{~mm}$ for the first 4 weeks, $0.4 \mathrm{~mm}$ for the second 4 weeks and $0.4 \mathrm{~mm}$ for the past 4 weeks. While the mean value for group II was $1.46 \pm 0.6 \mathrm{~mm}$ presented as $0.7 \mathrm{~mm}$ for the first 4 weeks, $0.4 \mathrm{~mm}$ for the second 4 weeks, and 0.36 for the past 4 weeks (Table 1).

There was no statistically significant difference between group I and group II as far as the total amount of tooth movement (Table 2).

Table 2: The mean, standard deviation (SD) values of Total percentage of change in tooth movement (W1 and W12)

\begin{tabular}{lll}
\hline Variables & Total percentage of change \\
\cline { 2 - 3 } & Mean & SD \\
\hline Group I & 5.21 & 1.14 \\
Group II & 5.81 & 2.71 \\
p-value & $0.660 \mathrm{~ns}$ & \\
\hline${ }^{*}$ Significant $(p<0.05)$ ns: Non-significant $(p>0.05)$.
\end{tabular}

\section{Histological findings}

The tension side in group I: Revealed osteoblastic activity lining the socket wall. The mean number of the osteoblasts was 19 cells. The newly formed alveolar bone showed different lamellar orientation and separated from the old bone by deeply stained basophilic reversal line. The thickness of the newly formed alveolar bone seemed to be even throughout the socket wall. The PDL fibers showed regular arrangement. Dilated blood vessels were obvious (Figure 4).

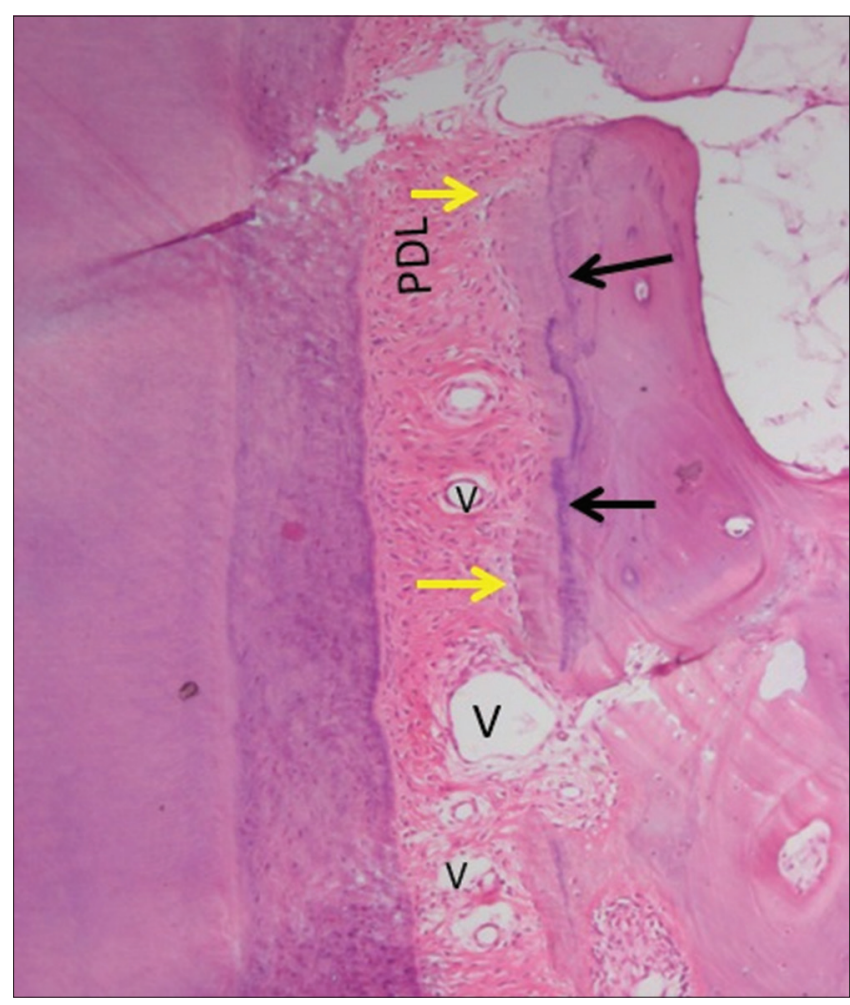

Figure 4: Photomicrograph of the tension side of group I showing reversal line (black arrows), osteoblasts (yellow arrows), irregularly arranged PDL fibers and dilated blood vessels (V). H and $E \times 100$

The tension side group II: revealed heavy osteoblastic activity lining the socket wall. The mean number of the osteoblasts was 33 cells. The newly formed alveolar bone appeared with different lamellar orientation and separated from the old lamellar bone by deeply stained basophilic reversal line. The thickness of the newly formed alveolar bone was uneven. The PDL fibers were irregularly arranged. Dilated blood vessels were obvious. Multiple giant macrophages were noticed at the fiber's insertion ends (Figure 5).

The compression side group I: revealed osteoclastic activity lining the socket wall. The mean number of the osteoclasts was 4 cells. Multiple Howship's lacunae delineated the socket surface. The PDL was highly compressed. Resorptive root surface was obvious and lined with cementoblasts in attempt for repair. Odontoclasts were noticed in the PDL near intact root surface a clue for continuation to the process of root resorption (Figure 6). 


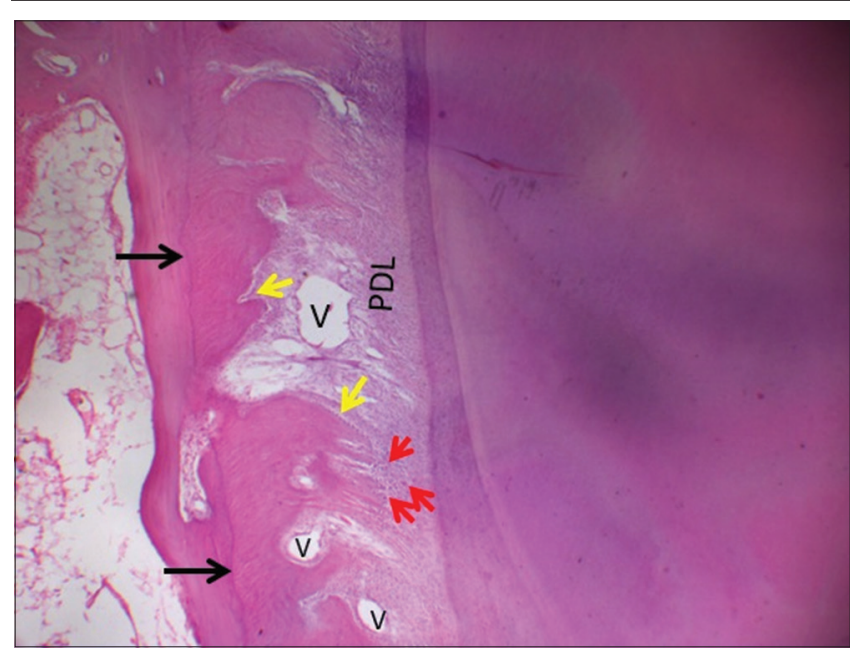

Figure 5: Photomicrograph of the tension side of group I/ showing reversal line (black arrows), osteoblasts (yellow arrows), macrophage (red arrows), irregularly arranged PDL fibers and dilated blood vessels (V). $H$ and $E \times 100$

The compression side group II: revealed greater osteoclastic activity lining the socket wall more than group I. The mean number of the osteoclasts was 6 cells. Multiple Howship's lacunae delineated the socket surface. The PDL was slightly compressed due to high osteoclastic activity that relieved the applied force. Resorptive root surface was obvious and lined with either odontoclasts indicating active root resorption, or cementoblasts in attempt for repair (Figure 7).

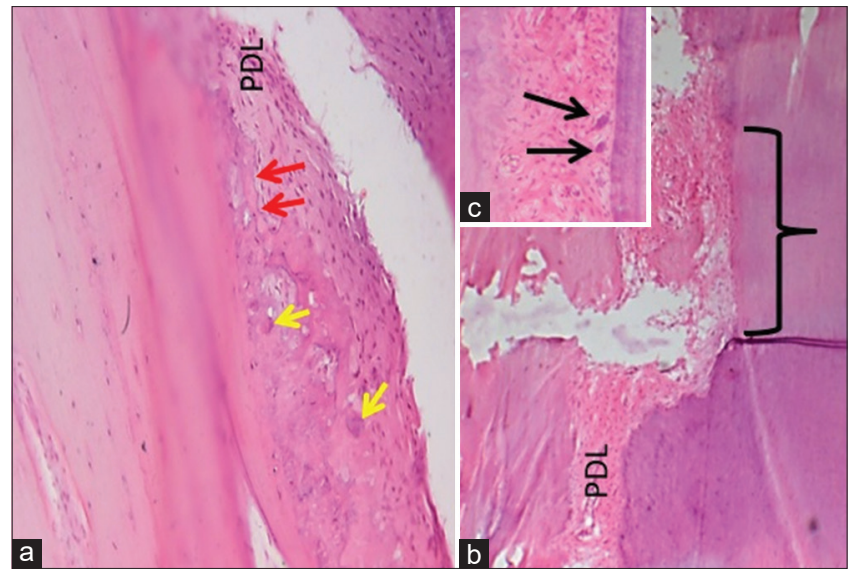

Figure 6: Photomicrograph of the compression side of group showing; (a) Howship's lacunae (red arrows) and osteoclasts (yellow arrows). (b) resorped root surface (brace). (c) inset showing odontoclasts (black arrows) $H$ and $E \times 100$

\section{Discussion}

This study focused on the rate of tooth movement using elastomeric chain reactivation every one versus 4 weeks in the canine model and its implication on the supporting structures.

The remodeling cycle and the metabolic rate in the canine model was reported by Reinwald et al. [5] to

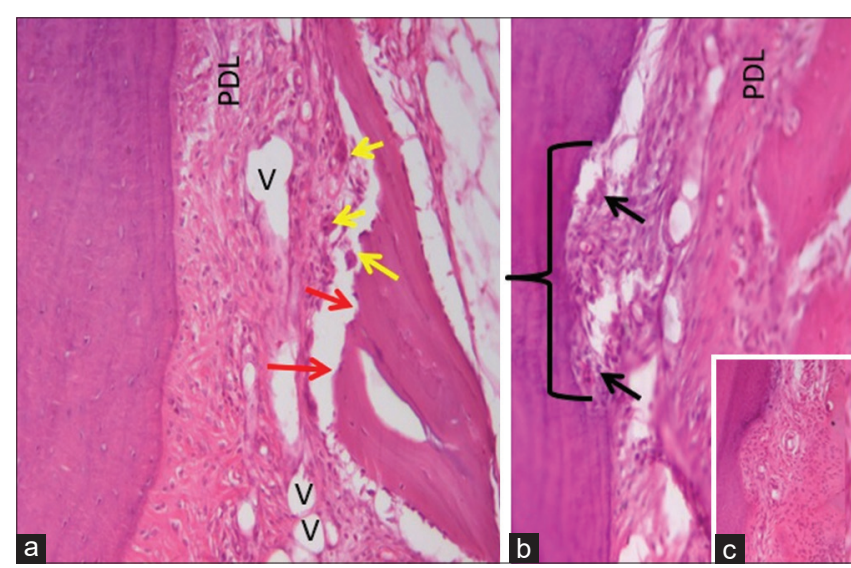

Figure 7: Photomicrograph of the compression side of group II showing; (a) Howship's lacunae (red arrows) and osteoclasts (yellow arrows). (b) resorped root surface (brace) and odontoclasts (black arrows). (c) inset showing resorped root surface with cementoblast lining. $H$ and $E \times 100$

be half that of humans hence reactivation in this study was performed every 1 and 4 weeks which corresponds to 2 and 8 weeks, respectively in the human body.

Similarly, Ren et al. [6] revealed that dogs' tissues reacted similar to human tissues as far as orthodontic tooth movement (OTM). They had the ability to tolerate surgical procedures and they showed a very small difference between the size and anatomy of the periodontal ligament and the alveolar bone. In addition, canine model provide adaptation in response to bodily tooth movement according to Ibrahim et al. [7]

The custom made appliance employed for tooth movement in the current study was similar to those described by Nakamto et al., [8] El Sharaby et al. [9] and Farid et al. [10]. Such appliance design would assure a favorable sliding rather than tipping type of tooth movement. Mabula et al. [11] depicted an appliance design of a Niti closed coil spring applied directly on the teeth which resulted in a tipping type of OTM as reported in their study. On the other hand Ma et al. [12] used a Niti closed coil spring on conventional brackets.

The orthodontic force applied using the power chain was $150 \mathrm{~g}$ in the left and right side as described by El Sharaby et al. [9] and Rashid et al. [13] Elastomeric chain was attached from a buccal hook on the second premolar crown to a buccal hook on the fourth premolar crown as described by Pilon et al. [14] Various force levels were reported in the literature ranging between 10 and $300 \mathrm{~g}$ [15], [16]. Heavier forces were not nominated to avoid possible unfavorable tissue reaction which might obscure the results of the study. Besides, as the elastomeric chains show a loss of force after initial stretching, they were pre-stretching before experimental use was performed so that they maintain the calibrated force as reported by Pilon et al. [14].

According to Bohl et al., [17] Rashid et al. [13] and Leeuwen et al. [18] measurements of the amount 
of tooth movement were performed every week. Even though Pilon et al. [14] measured the tooth movement twice a week and attached new pre-stretched elastics when a deviation of more than $5 \%$ of the desired force level was registered so that they could maintain constant force level throughout their experiment. This approach almost secured a continuous force that was not intended in the present study.

Decalcification of the specimens was done by formic acid and sodium citrate technique for better results than nitric acid as recommended by Choube et al. [19] who reported that the formic acid sodium citrate has less harming effect on cellular properties in addition to preserving staining quality. Staining with H\&E was carried out in the current study. Mostafa et al., [20] Sharaby et al. [9] and Ma et al. [12] reported the use of decalcified sections stained with H\&E. The present study was conducted to evaluate the supporting structure including the PDL which is better elucidated in decalcified rather than ground sections.

The tooth displacement curve of both groups followed the classic tooth displacement curve which consisted of three phases (initial, lag and acceleration). By applying the three phases of the tooth displacement curve on the clinical results of this study, the initial phase into which the highest amount of force occurred was $1^{\text {st }}$ and $2^{\text {nd }}$ weeks for the two groups. This was because of the orthodontic force and the width of the periodontal ligament is reduced on the pressure side [14]. Lag phase was found between $3^{\text {rd }}$ week and $9^{\text {th }}$ week as the tooth movement was almost constant for the two groups. Acceleration phases were seen after $9^{\text {th }}$ week as the tooth movement started to increase again.

When comparing between the two groups, there was no significant difference concerning the total amount of tooth movement as the mean value for group I was $1.44 \pm 0.5 \mathrm{~mm}$ with $0.64 \mathrm{~mm}$ for the first 4 weeks, $0.4 \mathrm{~mm}$ for the second 4 weeks and $0.4 \mathrm{~mm}$ for the last 4 weeks. While the mean value for group II was $1.46 \pm 0.6 \mathrm{~mm}$ with $0.7 \mathrm{~mm}$ for the first 4 weeks, $0.4 \mathrm{~mm}$ for the second 4 weeks and 0.36 for the past 4 weeks.

The results of this study were in agreement with results of $\mathrm{Kim}$ et al. [21]. They studied the effect of the piezo-puncture procedure on the rate of tooth movement using a NITI coil spring. Kim et al. [21] reported a rate of tooth movement of $0.72 \mathrm{~mm}$ in 6 weeks compared to $0.79 \mathrm{~mm}$ and $0.84 \mathrm{~mm}$ for group I and II, respectively. Likewise, Dixon et al. [22] compared the rates of orthodontic space closure for using active ligatures, polyurethane power chain, and nickel-titanium coil springs. The mean rates of space closure were $0.35 \mathrm{~mm} / \mathrm{month}$ for active ligatures, $0.58 \mathrm{~mm} / \mathrm{month}$ for power chain, and $0.81 \mathrm{~mm} / \mathrm{month}$ for NiTi springs. On the other hand, Mostafa et al. [20] acknowledged a tooth movement in the control group of $2.33 \mathrm{~mm}$ in 5 weeks compared to $1 \mathrm{~mm}$ tooth movement in the first 4 weeks achieved by Lino et al. [23].
These differences may be attributed to the appliance design as in the current study a $1 \mathrm{~mm}$ stainless steel wire passing through a metal tube was employed to ensure bodily movement which require 4.19 times the force required for tipping movement as reported by Lodaya et al. [24] Moreover, the tube wasn't wide enough for the wire to ensure bodily movement with minimal friction. This could have produced friction between the wire and the tube as reported by Husain et al. [25] who reported that frictional force was directly proportional to wire dimension. Mostafa et al. [20] and Lino et al. [23] conversely, implemented a nonsliding mechanics in their study. The Force decay of elastomeric chains could be another reason for the difference in the rate of tooth movement among studies. Halimi et al. [26] concluded that the force delivered by elastomeric chains decays rapidly over time, affecting their mechanical properties and clinical efficacy when studied in either human saliva or laboratory test media.

The histologic results were in acceptance with Mostafa et al., [20] Lino et al. [23] and Kim et al. [21]. The histological findings of the supporting structures in group II were more favorable than group I. This could be due to at reactivation interval of group II provided periods of rest which was reflected favorably on the cell proliferation in the supporting tissues [2]. This allowed for continuing the process of new bone formation, repairing root resorption and remodeling of the PDL. In their study to evaluate tooth movement in dogs after 4 weeks follow-up Mostafa et al. [20] reported active bone remodeling in the histological results when compared the corticotomy facilitated versus standard tooth movement techniques.

\section{Conclusion}

1. Altering the reactivation interval of the elastomeric chains from 4 to 1 week in the canine model doesn't seem to have a significant impact on the rate of OTM

2. 4 weeks reactivation interval showed a more favorable tissue reaction associated with OTM when compared to one week reactivation interval as evident from the greater capacity for bone formation at the tension side together with lesser compression of the PDL and attempts of repair of root resorption at the compression side.

\section{References}

1. Proffit WR, Fields HW, Sarver DM. Contemporary Orthodontics. St. Louis: Mosby Elsevier; 2007. 
2. Krishnan V, Davidovitch Z. Cellular, molecular, and tissuelevel reactions to orthodontic force. Am J Orthod Dentofac Orthop. 2006;129(4):469.e1-32. https://doi.org/10.1016/j. ajodo.2005.10.007

PMid:16627171

3. Ren Y, Maltha JC, Kuijpers-Jagtman AM. Optimum force magnitude for orthodontic tooth movement: A systematic literature review. Angle Orthod. 2003;73(1):86-92. https://doi. org/10.1043/0003-3219(2003)073<0086:OFMFOT>2.0.CO;2 PMid: 12607860

4. Bancroft JD, Gamble M. Theory and Practice of Histological Techniques. Philadelphia, PA: Elsevier Health Sciences; 2008.

5. Reinwald $S$, Burr D. Review of nonprimate, large animal models for osteoporosis research. J Bone Miner Res. 2008;23(9):135368. https://doi.org/10.1359/jbmr.080516 PMid: 18505374

6. Ren Y, Maltha JC, Van't Hof MA, Kuijpers-Jagtman AM. Optimum force magnitude for orthodontic tooth movement: A mathematic model. Am J Orthod Dentofac Orthop. 2004;125(1):71-7. https:// doi.org/10.1016/j.ajodo.2003.02.005

PMid: 14718882

7. Ibrahim AY, Gudhimella S, Pandruvada SN, Huja SS. Resolving differences between animal models for expedited orthodontic tooth movement. Orthod Craniofacial Res. 2017;20:72-6. https://doi.org/10.1111/ocr.12175

PMid:28643903

8. Nakamoto N, Nagasaka H, Daimaruya T, Takahashi I, Sugawara J, Mitani $\mathrm{H}$. Experimental tooth movement through mature and immature bone regenerates after distraction osteogenesis in dogs. Am J Orthod Dentofac Orthop. 2002;121(4):385-95. https://doi.org/10.1067/mod.2002.122368

PMid:11997763

9. El Sharaby FA, El Bokle NN, El Boghdadi DM, Mostafa YA. Tooth movement into distraction regenerate: When should we start? Am J Orthod Dentofac Orthop. 2011;139(4):482-94. https://doi.org/10.1016/j.ajodo.2009.05.041

PMid:21457859

10. Farid KA, Mostafa YA, Kaddah MA, El-Sharaby FA. Corticotomyfacilitated orthodontics using piezosurgery versus rotary instruments: An experimental study. J Int Acad Periodontol. 2014;16(4):103-8.

PMid:25654963

11. Mabula F, Zhuang Y, Guo W, You D, Lin S. Effects of bone regeneration materials and tooth movement timing on canine experimental orthodontic treatment. 2018;88(2):171-8. https:// doi.org/10.2319/062017-407

PMid:29154676

12. Ma Z, Wang Z, Zheng J, Chen X, Xu W, Zou D, et al. Timing of force application on buccal tooth movement into bone-grafted alveolar defects: A pilot study in dogs. Am J Orthod Dentofac Orthop. 2020;159(2):e123-34. https://doi.org/10.1016/j. ajodo.2020.09.010

PMid:33342675

13. Rashid A, EISharaby FA, Nassef EM, Mehanni S, Mostafa YA. Effect of platelet-rich plasma on orthodontic tooth movement in dogs. Orthod Craniofacial Res. 2017;20(2):102-10. https://doi. org/10.1111/ocr.12146 PMid:28414871

14. Pilon JJ, Kuijpers-Jagtman AM, Maltha JC. Magnitude of orthodontic forces and rate of bodily tooth movement. An experimental study. Am J Orthod Dentofacial Orthop. 1996;110(1):16-23. https://doi.org/10.1016/ S0889-5406(96)70082-3

\section{PMid:8686673}

15. Nakano T, Hotokezaka H, Hashimoto M, Sirisoontorn I, Arita K Kurohama T, et al. Effects of different types of tooth movement and force magnitudes on the amount of tooth movement and root resorption in rats. Angle Orthod. 2014;84(6):1079-85. https://doi.org/10.2319/121913-929.1

\section{PMid:24754797}

16. Yee JA, Türk T, Elekdağ-Türk $S$, Cheng LL, Darendeliler MA Rate of tooth movement under heavy and light continuous orthodontic forces. 2009;136(2):150.e1-9; discussion 150-1. https://doi.org/10.1016/j.ajodo.2009.03.026 PMid:19651334

17. Von Böhl M, Maltha J, Von Den Hoff H, Kuijpers-Jagtman AM. Changes in the periodontal ligament after experimental tooth movement using high and low continuous forces in beagle dogs. Angle Orthod. 2004;74(1):16-25. https://doi. org/10.1043/0003-3219(2004)074<0016:CITPLA>2.0.CO;2 PMid:15038486

18. Van Leeuwen EJ, Kuijpers-Jagtman AM, Von den Hoff JW, Wagener FA, Maltha JC. Rate of orthodontic tooth movement after changing the force magnitude: An experimental study in beagle dogs. Orthod Craniofacial Res. 2010;13(4):238-45. https://doi.org/10.1111/j.1601-6343.2010.01500.x PMid:21040467

19. Choube A, Astekar M, Choube A, Sapra G, Agarwal A, Rana A. Comparison of decalcifying agents and techniques for human dental tissues comparison of decalcifying agents and techniques for human dental tissues. Biotech Histochem. 2018;93(2):99108. https://doi.org/10.1080/10520295.2017.1396095 PMid:29313383

20. Mostafa YA, Fayed MM, Mehanni S, El Bokle NN, Heider AM. Comparison of corticotomy-facilitated vs standard toothmovement techniques in dogs with miniscrews as anchor units. Am J Orthod Dentofac Orthop. 2009;136(4):570-7. https://doi. org/10.1016/j.ajodo.2007.10.052 PMid:19815161

21. Kim Y, Kim S, Yoon H, Lee PJ, Moon W, Park Y. Effect of piezopuncture on tooth movement and bone remodeling in dogs. Am J Orthod Dentofac Orthop. 2013;144(1):23-31. https:// doi.org/10.1016/j.ajodo.2013.01.022 PMid:23810042

22. Dixon V, Read MJ, Brien KD, Worthington HV, Mandall NA A randomized clinical trial to compare three methods of orthodontic space closure. J Orthod. 2002;29(1):31-6. https:// doi.org/10.1093/ortho/29.1.31

PMid:11907307

23. Article $\mathrm{O}$. Acceleration of orthodontic tooth movement by alveolar corticotomy in the dog. Am J Orthod Dentofacial Orthop. 2007;131(4):448.e1-8. https://doi.org/10.1016/j. ajodo.2006.08.014 PMid:17418709

24. Lodaya SD. Orthodontic force distribution: A three-dimensiona finite element analysis. World J Dent. 2010;1(3):159-62.

25. Husain N, Kumar A. Frictional resistance between orthodontic brackets and archwire: An in vitro study. J Contemp Dent Pract. 2011;12(2):91-9. https://doi.org/10.5005/jp-journals-10024-1015 PMid:22186750

26. Halimi A, Azeroual MF, Doukkali A, El Mabrouk K, Zaoui F. Elastomeric chain force decay in artificial saliva: An in vitro study. Int Orthod. 2013;11(1):60-70. https://doi.org/10.1016/j. ortho.2012.12.007

PMid:23375920 